\title{
The Yummy Side of Hallyu: A Critical Autoethnography Dina Magdy ElDakhakhny
}

The spread of the increasingly popular Korean cultural products worldwide at the turn of the millennium is commonly referred to as Hallyu, or the Korean Wave. Literature on Hallyu is often written from the Korean perspective, focusing on its success in neighboring Asian countries, and the USA. The experiences and perspectives of cultural outsiders are largely absent from this corpus.

Inspired by this perceived gap, my paper begins with my chosen methodology, autoethnography: the study of the self in the context of culture, with a focus on individual experiences and personal accounts. After a brief introduction to Hallyu and what made it resonate with me on a personal level, I discuss how I first became aware of the problematic issue of Korean halal food and how this problem was expounded when I came to study in Korea. Finally, I refer to a few efforts on the side of Korea, discussing their effectivity in the face of this problem, and outline the implications of the food problematic.

Keywords: Autoethnography, halal food, Hallyu, Islam, Korea

\section{Disclosure}

When I first decided to write about my experience with Hallyu, I was very excited but also anxious. It is exciting to share my personal encounter with Hallyu, because I had not encountered any experiences similar to mine. I felt that the personal and emotional investment was finally paying off since it allowed me to experience and later pen down a different take on Hallyu. Yet, I was also very worried about what I will write. For one, it is more difficult to open up about personal experiences than it is to use a certain theoretical framework to analyze a text or a literary work. One lays oneself bare and becomes vulnerable to trivializing comments and often harsh criticism. Readers might also read the personal account as a generalized experience, which it is not. I do not consider myself representative of Islam, Alexandria, or foreigners in Korea.

My life in Egypt has been largely untraditional. In fact, one of my main concerns growing up was where to place myself in society. My parents sent me to the only German school in Alexandria; it is one of three 
German schools in all of Egypt. We were taught by German teachers and supervised by German nuns, an unusual and interesting arrangement in a predominantly Muslim Arab country. Early on, I realized that I was not an "authentic" Egyptian. My exposure to German culture in school made me a bit of a foreigner in my own country; yet growing up steeped in Egyptian traditions, I felt distinctly non-German.

My mistake at that point was trying to neatly place myself in one of the two separate cultural spheres. When two cultures meet, it is rather limiting to consider the encounter in terms of binary opposites where one inevitably dominates the other, or through the lens of a Hegelian process of synthesis and sublation. The trap of false binaries detracts from the complexity of the process of identity formation which is always in progress and in flux, especially in a multi-cultural context (Bhabha, 1994).

Instead, according to Homi Bhabha (1990), one should look at culture in terms of numerous and varied praxes existing side by side, abseits, in order not to experience cultural encounters as sites of absence or loss. "What is at issue is ... the regulation and negotiation of these spaces that are continually, contingently, 'opening out', remaking the boundaries, exposing the limits of any claim to a singular or autonomous sign of difference-be it class, gender or race" (p. 219). This turn of mind allows one to be "neither One nor the Other but, something else besides, in-between" (p. 219), inhabiting a third space drawing on both. When I started high school, I realized that this liminal third space is not so bad after all, and for college, I went against the grain once again. I turned down the chance to study at the most prestigious departments in Alexandria (i.e. medicine, dentistry, pharmacy, and engineering) and decided in favor of the humanities; I wanted to study human nature through literature, instead. This choice cemented my position as an outsider. My opinions and views should, therefore, be read as my own and not as illustrative of my culture.

My experience in Korea is also not particularly representative. According to reports ("Foreign Residents," 2011; Korea Immigration Service, Ministry of Justice, 2015) and my own observations, most immigrants and foreign students in Korea are Asians from neighboring countries, and Americans, the latter perhaps connected to the strong military presence in Korea.

A small percentage of Asian foreigners are Muslims from Malaysian and Indonesian backgrounds. They tend to gather in closed communities connected by websites and chat rooms, written mostly in their native languages, which function as help forums on which they discuss their troubles and issues. In contrast, scattered individuals from different cultural backgrounds, who find themselves deprived of a supportive network, experience difficulties differently. 
Experiences of workers, whether Muslim or otherwise, are also quite different. They face problems ranging from exploitation, blackmail, and language barriers to injuries on the job and health care issues. Documentaries such as Changhee Chun's Lost Baggage: Documentary on Migrant Workers in South Korea (2008) attempt to grapple with such issues and bring them to the forefront of human rights discussions. My voice, on the other hand, does not speak up on other people's behalf; instead it documents my own experience.

The following section will introduce my chosen methodology, autoethnography, detailing how my experience that is largely absent from already existing discourse prompted me to document my problem, followed by a brief introduction to Hallyu and my first contact with the cultural movement. I also outline why the cultural phenomenon resonates with me on a personal level, how I first became aware of the problematic issue of Korean halal food and how it was expounded during my stay in Korea as a student. Finally, I discuss Korean efforts to address this problem, and the significance and implications of this food issue will be highlighted.

\section{Methodology}

In light of the particularity of my experience, the most appropriate format and methodology that presented itself to me was autoethnography. Autoethnography is

A qualitative research method that focuses on self as a study subject but transcends a mere narration of personal history. [Heewon] Chang $(2008,2011)$ defines [autoethnography] as a research method that enables researchers to use data from their own life stories as situated in sociocultural contexts in order to gain an understanding of society through the unique lens of self. (Chang, Ngunjiri, \& Hernandez, 2013, p. 18)

Documenting the research process (-graphy) on the self (auto-) and culture (-ethno-), autoethnographic accounts range in style between the more personal and autobiographical to the more theoretical and analytic (Chang et al., 2013). The methodology combines what are often perceived to be two antagonistic tendencies into a fragile balance that constitutes a new dimension of knowledge production. The resulting accounts offer a new lens of looking at culture; "autoethnographic interpretation...transcends mere narration of their past to help researchers reach explanations of the sociocultural phenomena connected to the personal" ( p. 19). 
Ethnography at its outset depended upon the othering of the examined community, often limiting it to a prescribed and monolithic entity that is incapable of further progress or of diversity (Nader, 2011). Defamiliarizing the "primitive" society at hand and establishing clear-cut boundaries set the scholar on a higher level on the binary scale. Ethnographers who broke these unspoken rules of early ethnography were banned from writing and their motives and works were questioned and scrutinized. Slowly with the "democratization" of academia, intersections and similarities were highlighted and celebrated instead. Turning the focus of the study inwards and including the self as a research subject within the cultural context further served to eliminate these delineations, particularly when the researcher belonged to a minority group. The newly emerged autoethnography thus "legitimates first-person accounts of discrimination and difference and can therefore aid in the critique of colonialism, racism, sexism, nationalism, regionalism, and ethnocentrism" (Boylorn \& Orbe, 2014, p. 237). Since individual accounts grapple with issues from a different angle whether it be race, sexuality, gender, age, dis/ability, education, or religion among other differentiating factors, autoethnography serves as a revisionist methodology to counter traditional research tools which were narrow and limiting in their perspective (Ellis, Adams, \& Bochner, 2011).

"Autoethnographic stories are artistic and analytic demonstrations of how we come to know, name, and interpret personal and cultural experience" (Adams, Jones, \& Ellis, 2015, p. 1). Dealing with loss, love, absences, violence, spirituality, education, and medical issues among many diverse topics, autoethnographies tend to focus on life-changing events and turning points, stories that in being written serve as cathartic therapy for the writers and enable them to process why certain episodes happened the way they did with the benefit of hindsight and critical analysis. In writing these stories, researchers engage with their topic from various angles and numerous theoretical frameworks. Theorizing in the context of autoethnography therefore does not imply the utilization of a rigid theory, but as Boylorn and Orbe (2014) explain, it rather

Takes a variety of forms and can be engaged through multiple points of contact and streams of processing. Theorizing, as opposed to theory, 'captures the essence of something alive, fluid, and current' and cannot be regulated to rigid conceptualizations of what should or should not be counted as scholarship. (p. 235)

While celebrated by some, myself included, autoethnography is not an unproblematic methodology in and of itself. The significance of one personal 
account for academia, the emotional and non-objective viewpoint, and the concern over the verification of the accounts are among the major issues raised against autoethnography. These questions are, of course, valid and quite constructive when they are asked for the sake of furthering knowledge and not simply from a condemning classicist and elitist standpoint:

For the most part, those who advocate and insist on canonical forms of doing and writing research are advocating a White, masculine, heterosexual, middle/upper-classed, Christian, able-bodied perspective [which could be argued to be skewed and biased, overlooking the experiences of marginalized minorities]. Following these conventions, a researcher not only disregards other ways of knowing but also implies that other ways necessarily are unsatisfactory and invalid. (Ellis et al., 2011, n.p.)

In that vein autoethnographies are often judged as "insufficiently rigorous, theoretical, and analytical, and too aesthetic, emotional, and therapeutic" (Ellis et al., 2011, n.p.); they are condemned as "a form of 'soft research' or 'me-search' that is atheoretical, ungeneralizable, and self-absorbed" (Boylorn \& Orbe, 2014, p. 235), even though by definition autoethnography centers on the individual experience. The researchers and autoethnographers "are thought to not only use supposedly biased data, but are also navel-gazers, self-absorbed narcissists who don't fulfill scholarly obligations of hypothesizing, analyzing, and theorizing" (Ellis et al., 2011, n.p.).

Ironically, that is precisely the strength of autoethnography. Unlike classicistapproaches, thereisaself-consciousmovetowardstheincorporation of the researchers into the knowledge they produce. Autoethnography substitutes "doing research ... [for] storying lives as research" (Adams et al., 2015, p. 5). Objectivity and distance in conducted research create knowledge gaps due to "the inability of [scientific methods] to create insight about the particularities, nuances, and complexities of identities, relationships, experiences, and cultures, as well as the methodological disregard of stories and storytelling and the bias against care, emotions, and the body" (Adams et al., 2015, p. 16). Previously this objectivity was highlighted to protect "the illusion that ... [the] objects of study were unrelated to the subjectivity that produced knowledge about them" (Butz \& Besio, 2009, p. 1662). Such an approach clearly aims to disguise how we are social beings shaped by certain ideological and power structures, which influence how we perceive the world around us. In epistemological terms this approach both acknowledges that subjectivity colors the lens through which we 
view the world and aims to mask the fact that there is a person behind the research by eliminating the subjective "I" altogether. Autoethnography on the other hand does not emphasize this distance or deny how the researcher is "thoroughly implicated in the phenomena that he or she documents" (Atkinson, 2006, p. 402); on the contrary, the autoethnographer is explicitly positioned as both writer/observer and participant (Hoppes, 2014). Ellis, et al. (2011) further explained that:
Autoethnography ... eschew[s] rigid definitions of what constitutes meaningful and useful research; this approach also helps us understand how the kinds of people we claim, or are perceived, to be influence interpretations of what we study, how we study it, and what we say about our topic. (n.p.)

The bottom line of the debate is whether or not autoethnography contributes to knowledge production. Using this as my point of departure, the question that needs to be answered is: what is the value of this project and what kind of knowledge will it produce? Are these just ramblings that are perhaps better suited for a magazine spread or a blog? Or is there an actual contribution to the knowledge base buried somewhere beneath the personal stories and anecdotes? The answer to these questions lies within the salient factor of perspective. My background, my education, and my circumstances shaped the lens through which I examine one facet of Hallyu. This unique standpoint should generate knowledge about this specific cultural encounter, which seems to need more exposure. In fact, over the past two years I have not encountered a single Korean who has any formal knowledge of Islam or has even heard the word halal, i.e. what is permissible to use, ingest or engage in according to Islamic guidelines, before.

What I attempt in the following pages is an examination of self in the context of culture; my autoethnographic account is meant to offer "specific knowledge about... [my own life], experiences, and relationships rather than general information about large groups of people" (Adams et al., 2015, p. 21). On the one hand, this is a narrative from below, a kind of subaltern autoethnography, as catalogued by David Butz and Kathryn Besio (2009). Middle Easterners have constantly been orientalized and represented by powerful "Selves" as ignorant, primitive, and hypersexualized Others, or more recently, within the increasingly popular stereotype of the angry religious fundamentalist and terrorist. Orientalism and Islamophobia have rendered us the object of many discussions, silencing our voices and robbing us of the chance to directly represent ourselves; instead, generous and benevolent Western scholars speak on our behalf. 
My account is also a kind of personal narrative or reflexive autoethnography (Ellis et al., 2011; Butz, \& Besio, 2009) since it revolves around my own experiences without recourse to research data collected from interviews or research subjects.

Throughout my account I do not pose as a cultural colonizer or privileged scholar, even though the culture I am grappling with is not my own. On the contrary, as a Muslim, an Arab, and a woman, I am a member of a variety of minority groups. Korea's concern with its position in Asia and its gaze towards the West and the USA are indicative of the underlying power play in global relations. However, I participate as a powerless entity whose experience is underrepresented in present discourse. This account therefore inverts the power dynamic present in early ethnography.

Though my account engages with the problematic of race and religion, it is not an exploration of identity formation in an overtly anti-Islamic country as is the trend in some of the narratives of Arabs/ Muslims in the USA post 9/11 (cf. Hamid, 2007; Jamal \& Naber, 2008; Khan \& Ecklund, 2012; Boylorn \& Orbe, 2014; Semaan, 2014). Though the topic could be deemed trivial and mundane, it is precisely this everyday quality that makes it important. Oftentimes the little things are taken for granted even though some thought could uncover hidden ideological implications underneath it all.

More than just a retelling of my personal fascination with food, this account explores the intersection and interaction of culture, religion, and food, and aims to highlight the resulting tension. It hinges upon my particular background and my position as a cultural outsider (an Egyptian), who is specifically Muslim (Christian Egyptians would not have these same issues).

Despite its controversial history, the goals and aims of autoethnography coincide with my own. Considering my position on the margins, autoethnography seemed even more appealing. I firmly believe that as long as we can generate new knowledge, the methodology, even if not accepted as scientific and analytical, is valid and worthwhile. Literary works generate knowledge through the fictionalized accounts of individual people's lives, and real, lived experiences can provide just as much or even more insightful knowledge. In a way, my attempt to document my story celebrates autoethnography by acknowledging the value of individual and personal experiences.

\section{What is Hallyu?}

In the 1990s Korea exported dramas to China, which were very favorably received, leading to the coinage of the term Hallyu (한류), or the Korean Wave, by Chinese media. Winter Sonata (H. Lee, 2002) and Dae Jang Geum 
(Jo, 2003) are the first two dramas usually associated with the spread of the first wave of Hallyu in China and Japan. Following the popularity of dramas in neighboring Asian countries, Korea started producing more cultural material to export.

In Korea, Hallyu is recognized as a means of dissolving Korea's long felt Han (Hanp'uri) and a source of pride (Cho, 2005; Kim \& Ryoo, 2007). Having been overpowered by Japan and China, both colonial superpowers, Korea can now find its place in the world and become a trendsetter in the region; in fact, due to the history of imperialism in Asia, Korea emerges as a more palatable cultural trendsetter than either colonial superpower (Kim \& Ryoo, 2007).

Reasons for the success of Hallyu in Asia are believed to be geographical proximity, and the shared history and Confucian roots (Chua, 2010; Kim \& Ryoo, 2007). Hallyu is also perceived as a way of countering Western and American cultural hegemony (Cho, 2005; Kim \& Ryoo, 2007) even though some concerned critics warn against Korean cultural imperialism and call for cultural diversity within the movement (Shim, 2006).

In the West, Hallyu is popular because it comes across as a combination of East and West. It is culturally situated between the very Chinese Hong Kong Kung Fu movies and odorless Japanese cultural products (Kim \& Ryoo, 2007). The liberalization and modernization of certain industries in Koreasuch as media, IT, electronics, and tourism among others, which facilitate the spread of Korean cultural and material content-also contribute to the success of Hallyu worldwide (Cho, 2005; Shim, 2006). Whereas Hallyu started with dramas, nowadays it includes variety shows, movies, music, food, martial arts, traditional stamps, and much more (Cho, 2005; Shim, 2006).

Most studies pertaining to Hallyu are rather emic in nature: they analyze the movement solely from the Korean perspective, even while situating Korea within a global context. Benefits for Korea-the statements about Korea and the status of Korea from the Korean perspective-take center stage. Adopting such a framework, the perspective of cultural outsiders is unfortunately neglected to a great extent.

What Professor Ko Jeongmin (Hongik University Business School) stated in the KBS World $10^{\text {th }}$ Anniversary Special is very insightful and should be taken into consideration ("Hallyu Now," 2013). If Korea wants to become more global, it should think of Hallyu in terms of bilateral exchange, rather than a one-sided transmission. Korea should import other cultures, too, and accommodate cultural outsiders to reach a much wider audience ("Hallyu Now," 2013). After all, culture is a sensitive issue being closely tied with (national) identity; Hallyu could inspire a backlash 
if these other cultures are not accommodated. Cultural researchers must adopt an etic framework to complement the Hallyu knowledge base. Here autoethnographic accounts provide fragments missing from the greater picture, which is also the purpose of this account. Rather than conforming to widely believed and unproblematic intercultural encounters circulated by the official Hallyu media narratives, documented individual experiences-including mine-problematize intercultural encounters, render them multilayered and complex, and venture into territories well below the radar. Instead of providing a success story in which Hallyu helps me through troubles, brings me to Korea, and overall improves the quality of my life-which is the content of a lot of the documentaries on Hallyu-I provide an account that unearths a moment of tension.

\section{Enter: Hallyu}

Autumn in My Heart (Yoon, 2000) and Winter Sonata (H. Lee, 2002) aired in Egypt in 2004. About a year later My Name Is Kim Samsoon (Kim, 2005) followed. The series inspired some interest in Korea and Korean culture. Due to the culture's popularity, Ain Shams University in Cairo opened a new Korean department in 2005 (Iglauer, 2012), and over the years a few Korean restaurants also opened in Cairo. However, in Alexandria, where I live, the Korean presence is not as apparent; there are no Asian markets, Korean restaurants, or Korean cultural centers. Therefore, my initiation into Hallyu came much later, at the hands of my cousins.

My cousins live in Saudi Arabia and visit Egypt during the holidays. In the Gulf, there is a substantial Asian population; half of all foreigners in the Gulf countries in 2004 were reported to be Asians (Kapiszewski, 2006). Although there is little contact between natives and Asians in terms of cultural exchange, these Asians create isolated cultural islands where Asian food markets, cultural centers, and shops cater to them. Due to this proximity, my cousins first came in touch with other Asian cultures.

During my final year of high school, my cousins introduced me to Japanese anime, and they continued to introduce me to Japanese, Taiwanese, and, finally, Korean series until I graduated from university. Due to the cultural gap, I was skeptical and doubted whether I could enjoy the series, but by the time I started watching Korean series, I was a convert! I noticed that I did not need time to get used to Korean series unlike my experience with Japanese and Taiwanese ones. I could relate instantly, and of all the Asian shows that I watched, I liked Korean ones best. I started listening to Korean music, too, and tried to pick up Korean words while I was watching. Thus began my journey with Hallyu. 


\section{"Ok! But Why Korean?"}

Hallyu entered my life unexpectedly, despite my initial skepticism. Everybody-including me-started to ask why I enjoyed watching Korean series and variety shows. Why did I enjoy Korean music? What makes all these cultural products attractive to me? It dawned on me that our cultures are very similar in many unexpected ways; the similarities between the Egyptian and Korean cultures abound. In fact, between the American series flooding our broadcasting stations and the Korean series that I had to watch online, the latter hit closer to home.

The first point of attraction for me was the language. Growing up, I enjoyed learning new languages, which was infinitely helpful when I studied German, English, and French at school. Of the Asian series that my cousins gave me I found myself listening closely during the Korean ones. This is of course very subjective, but I felt that Japanese is dry and Chinese is rough. In contrast, Korean sounds very soft and musical to my ears; in my opinion it is the equivalent of French in Asia. It surprised me to discover that when it comes to songs out of translated musicals, I would like the Korean version better in almost all cases.

Mingled with that admiration for the language and its sounds was the fascination of finding conceptual similarities between Arabic and Korean. The common Korean greeting would be annyeonghaseyo (안녕하세요) that is translated into "Are you at peace?" or "Have you been at peace?" The Arabic equivalent is very similar; a habit derived from Islam is to greet whomever you chance to meet with the phrase assalamu alaykom wa rahmato Allah we barakaatoh (النسلام علنكم ورحمة الله وبركاته), which translates into, "Peace be upon you and God's mercy and His blessings."

Another similarity I discovered early on is the way older male and female relations are called. The tradition of calling an older male relative abeh (أبيــأـive pronounced like the French abbé) and an older female relative abla (أبلــــ (أبـة) was the result of the Turkish influence on Egyptian culture and is no longer practiced in contemporary Egypt. Korean has corresponding words: an older male relation is called oppa (오빠) and an older female is called eonnie (언니). Though it is unclear whether these similarities are coincidental or can be traced back to instances of cultural exchange on older trade routes like the Silk Road, the possibility of unearthing further points of intersection calls for more research on Hallyu.

Another similarity is the way in which family life and family values are esteemed. Unlike in the West, it is a matter of course for children in Egypt and in Korea to live with their parents until they get married or settle elsewhere. Egyptian children take in their parents and care for them personally instead of sending them to elderly homes or hospices. Similarly, 
in Korea, it is considered normal practice for three generations to live together in one house, if space allows. The strong family ties in Korea are a remnant of its Confucian history; Korean cultural products that depict them are therefore popular in other Asian countries (Chua, 2010). In Egypt, it is Islam rather than Confucianism that regulates these family ties. The concept called selat el rahem (صـلة الـرحم) lays a lot of emphasis on nurturing the relationship between family members, including extended family, friends, and neighbors. The family lives depicted in Korean media therefore do not seem too far removed from my own life in Egypt.

The reach of Hallyu and Korean cultural products in Asia is reminiscent of the role Egypt plays in the Arab world. It is well-known in the Middle East that Egypt is a trendsetter in the Arab world; as a singer or actor, if you want to succeed, you try your luck in Egypt. This probably goes back to the fact that Egypt has an accent that is almost neutral and easy to understand by other Arabs, whereas other Arab countries have very thick accents which are sometimes unintelligible to foreigners. Thus, Egypt helped launch the careers of a lot of singers and actors such as Fareed El Atrash and his sister Asmahan (actors/ singers- Syria), Sabah (actress/ singer- Lebanon), Warda (singer- Algeria), Nancy Ajram (singer- Lebanon), Lateefa (singer- Tunisia), Abd El Salam El Nabulsi (actor- Lebanon), Hend Sabry (actress- Tunisia), Dorra (actress- Morocco), Nour (actress- Lebanon) and many others along the years. Egyptian singers and actors are also well known and popular in the Arab world. The role Egypt plays as a cultural exporter is quite similar to the role Korea plays in Asia, exporting Hallyu products.

Whichever way I looked at it, it seemed to me that I was looking at a familiar, yet strange, version of my own life. Hallyu operated as a mode of defamiliarization; without coming too close to home, I could critically examine my society and myself in this distanced version that still allowed me to recognize myself. I could see things I did not notice in my daily life and safely critique what I did not like. On the other hand, cultural differences brought in a freshness and novelty: the setting, the language, the fashion sense, and ideals of femininity and masculinity were very different.

\section{The Honeymoon Is Over}

While getting to know Korea through series and variety shows, I soon noted a recurring sentiment; I always felt hungry. It was so severe that I decided only to watch if I was armed with a snack, or during a meal. Watching on an empty stomach became unbearable. One of the earlier variety shows I watched was Family Outing (Jang, 2008); the show cleverly promotes different locations in Korea. The family goes to different provinces for two days and a night. They play a lot of games, cook a dinner made of local 
produce together, and compete in a morning challenge. Losers prepare breakfast while the rest can go back to sleep until the meal is ready. Both main segments of the show feature meal preparation, which includes all stages like fishing, catching chickens, or harvesting vegetables and fruits.

Other series I watched include a lot of cooking and eating too. Flower Boy Ramyun Shop (Pyo, 2011), Pasta (U. Lee, 2010) and other series include food in their titles and posters. In the trendsetting Boys before Flowers (Group 8, 2009) there is a kimchi-making scene, obviously promoting Korea's staple side-dish. Shin Min Ah could very well be sponsored by a Hanu business in My Girlfriend Is a Gumiho (BON Factory, 2010), because every other scene was of her eating beef or talking about beef. The Reply 1997/1994/1988 series (Shin, 2012; Shin, 2013; Shin, 2016) all showcased several Korean dishes in almost every episode. Let's Eat (CJ E\&M, 2013), however, features the ultimate foodporn. In this show viewers can forget about plot and simply watch the glory that is food.

When you watch shows like these, you find yourself wanting to eat what the characters are eating. You find it appealing and you are curious about the taste. The natural outcome was that my best friend and I decided that we wanted to try the food ourselves, so we came up with a plan. My friend's father works in Kuwait, and she often visits him. On one such visit, she located a Korean supermarket and we Skyped while she was there to pick out the groceries together. The plan was to have a Korean food feast when she came back. Unfortunately, it turned out to be a disappointing experience. We bought Japchae sauce, Japanese noodles, Korean three minute curry, Kalbi sauce, and Ramyun. The Japchae sauce had been made with pork bone extract; the Japanese noodles had alcohol; the curry had beef extract; the Kalbi sauce had alcohol and cooking rice wine; and the Ramyun included beef soup. These ingredients may seem inoffensive to most people and, given that the ingredients are written on the packaging, we should not have been disappointed at all but there is a reason for our reaction.

First of all, as Muslims we are only allowed to eat halal food. "Halal [حلا]] is an Arabic word meaning 'lawful' and 'permissible"' (Park, 2013, n.p.). Halal food is prepared according to Islamic dietary guidelines; vegetables and grains in and of themselves are generally unproblematic and so is fish. The halal issue is more concerned with meats and alcohol. Muslims are not allowed to consume alcohol or pork at all (not even when alcohol is used in cooking and is supposed to evaporate during the process). While beef, lamb, and chicken are generally permissible, a lot hinges on how the animal is slaughtered.

The halal rules of slaughter are supposed to be more beneficial for us and more merciful to the animal. If the animal is not slaughtered in this 
manner, a practicing Muslim cannot consume any part of it. This is not just a question of the meat but also of animal fats (for instance, animal shortening) and enzymes (such as rennet which is used to make cheese). Halal guidelines thus extend to the consumption of gelatin, shortening, and rennet used in baked goods, chocolates, sweets, and cheese.

The problematic ingredients were also not listed in Arabic. Although the packaging included an Arabic label with a translation of the ingredients, the controversial ones were purposefully left out probably so that the products could enter the country despite Kuwait's import ban on non-halal products ("Kuwait: Import Requirement and Documentation," 2005). Skipping these problematic ingredients seems like the easiest way to smuggle these products into Kuwait. This, however, left us feeling cheated and duped. All the excitement amounted to nothing; all the money we spent was wasted and all the effort my friend put in was for nothing.

Yet, we still wanted to try Korean food. I hoped I would end up in Korea one day, and when I got accepted as a graduate student at Yonsei University in Seoul, I knew it was finally time. A little research showed that due to a growing Muslim population in Korea, there are halal restaurants and halalcertified products.

At the end of August 2014, I arrived in Seoul only to find my plans thwarted once more. The disappointment this time was greater since this experience was supposed to console me. I visited the sites of the corporations that apparently got halal certification. Lists of halal-certified products were nowhere to be found, with the exception of a few items used as examples: steamed rice, dried seaweed, mayonnaise, and kimchi (Park, 2013). The question that immediately poses itself is: why are they certifying unproblematic items to begin with? Moreover, it turns out that the elusive halal products are only exported abroad, and are not sold in Korea. Food giants and corporations secured the halal certification from neighboring Asian countries - such as India, Indonesia, Malaysia, and the Philippines (Park, 2013)—-to which they export these products.

An attempt to reach out to the Muslim population actually living in Seoul came in the form of the halal food court in Hanyang University which was opened in March 2013. Although the cafeteria is open to Muslims who are not enrolled at the university, it used to operate only two days a week, now four days, and the food is instantly sold out. What other options do Muslims have?

The Korea Tourism Organization and the Korean Food Foundation launched HalalKorea, a mobile application, in September 2015. Along with a qibla pointer (a compass pointing in the direction of the Kaa'ba in Mecca which Muslims have to face while praying) and prayer time alarms, this 
application includes a barcode scanner, which can be used on products to ascertain if they are halal or not. The database is unfortunately quite limited; I scanned barcodes of products around me, and not a single one was on their database. Two other features locate markets and restaurants offering halal food. Unfortunately, these too, are not unproblematic.

Eating out is not without its difficulties. Kim Hyo-jong, Secretary General of the Korea Halal Import Export Trade Association, reported that there are fewer than " 20 halal food restaurants in Seoul. It's extremely difficult to find halal food restaurants outside the capital" (as cited in Park, 2013, n.p.). Most of these restaurants are clustered in Itaewon, near the Seoul Central Mosque. The HalalKorea application basically directs the user to Itaewon for halal markets and restaurants. The problem is, you cannot go to Itaewon for every meal. Even if you do, Itaewon restaurants serve Indian, Malaysian, Indonesian, Pakistani, Egyptian, Turkish food, etc., but not Korean. There are only two small Korean halal restaurants; one opened in October 2014, and the other in February 2015.

Unfortunately, vegetarianism is also not widespread, so vegetarian variants will most likely not be available. Dishes that do not contain meat may include an odd piece of ham or spam. Often, even Korean soup dishes which do not technically contain meat are in fact meat based.

Muslims who observe the halal rule have therefore limited options. Some compromise while others adopt a Spartan lifestyle. Kim Hyo-jong further stated that a lot of "travelers had to eat uncertified food because there was no alternative, [or they skipped] meals for religious reasons" (as cited in Park, 2013, n.p.).

\section{Implications of the In/Ability to Consume Food}

Eating is a social practice and restrictions often have certain ideological implications: "If there is one sure thing about food, it is that it is never just food-it is endlessly interpretable-materialised emotion" (as cited in Xu, 2008 , p. 3). Food creates a sense of solidarity among members of the same community, and it also divides "along the lines of culture, region, race/ ethnicity, religion, gender, age, class, and sexuality-a hegemony that is exercised via appetite and desire. This hegemony is probably more effectively inscribed in us than other ideological hegemonies" (Xu, 2008, p. 4). Koreans abroad longing for Ramyun or kimchi are not only satisfying a temporary craving but are also recreating a connection with their motherland. In the works of Asian American writers, food and alimentary practices are often used to emblematize a dis/connection with the homeland, with the past, and with certain ideological constructs (Wong, 1993; Xu, 2008; Williams, 2010; Dalessio, 2012). 
Food is a powerful tool of inclusion and exclusion. Ingestion, the mediating act between the cultural symbol and the body, is therefore crucial (Wong, 1993). The inability to ingest underscores the inability to become integrated. The unassimilated body is distinctly isolated and disconnected from the community despite its proximity: "Strange bodies are precisely those bodies that are temporarily assimilated as the unassimilable within the encounter: they... [are] constructed through a process of incorporation and expulsion-a movement between inside and outside" (Ahmed, 2000, p. 54).

According to the dominant discourse, Hallyu presents itself as a noncolonizing and welcoming cultural movement, yet food is made available in a very particular and uncompromising form. Consumers of Hallyu participate in Korean food practices as they are or are simply excluded. The result is conformity or hunger. "[Frances M.] Lappé and [Joseph] Collins (1986) argue that hunger is the clearest sign of powerlessness, for hunger means one lacks the control to satisfy one's most basic subsistence need" (Counihan \& Kaplan, 1998, p. 2). Through food, Korea implements an alimentary and gastronomic hegemony that keeps foreigners visibly apart.

This issue also makes for quite a few awkward encounters and frustrating episodes. When friends and acquaintances try to offer me snacks and food, for instance, I have to turn down the nice gesture almost every time and explain why I cannot have any. End of term dinners also have these awkward moments when colleagues would try to find something I can have on the menu and come up with nothing. The food limitations make gatherings uncomfortable for me and for others who feel guilty for enjoying a meal I cannot share with them. These unfortunate circumstances position the Korean body as the normative, unmarked body that consumes food unhindered and "appears contained, enclosed and separate. We can consider such an unmarked body as a body which is at-home or in-place. Bodies that are marked as different from the human body, bodies that are (although in different ways) out of place, are hence excluded form the body politic" (Ahmed, 2000, p. 46). We are excluded from society and its microcosm, the dinner table, albeit in implicit and non-verbal terms which deliver the message just as compellingly.

While this is my experience, cultural Others in Korea may find it relevant. In my limited circle of acquaintances, a few individuals also have some dietary restrictions. Jewish Kosher diets are as challenging to maintain as halal diets. Though not for religious reasons, vegetarians and pescatarians face almost the same issues as well. Friends who suffer from food allergies also have horrible tales to tell where their question whether a certain item on the menu included a certain ingredient almost ended catastrophically due to the sneaky presence of the allergen in the dish. Lured to Korea by 
the spread of Hallyu and the appeal of Korean culture, my friends and I constantly struggle to find food in Korea without compromising our health, our beliefs, or ourselves. Naturally, if all of us were to gather, food would definitely be out of the question considering all the individual limitations.

It is also a shame that I currently live in Seoul unable to try halal Korean dishes. Traveling with my best friend in Korea, we also found it exceedingly difficult to sample representative food in different Korean provinces. We often found ourselves heading to the supermarket for fruits and safe snacks instead.

It is not a matter of unavailability, though, but rather lack of knowledge. There are halal chicken and meat factories just out of Seoul. Despite the location, their prices are similar to non-halal food. Why not make halal samgyettang (삼계탕) or halal bulgogi (불고기)?

The Hallyu movement is a very self-conscious one: series often have reflexive moments when intentional product placement is discussed. Every item onscreen is there to be promoted. The series King of Dramas (SSD/ Golden Thumb, 2012), for instance, exposes how directors go to great lengths to accommodate sponsors through ad placements. Although I was aware of product placement before the series-the recurrence of certain phones, coffee shops and delis is an obvious and deliberate form of endorsement-it surprised me to discover how producers went so far as to change the plot to feature products. King of Dramas reveals the amount of manipulation and promotion that goes into producing a show.

For Muslim viewers, products are strategically placed to pique our interest, and attract our attention, yet we remain tantalized by the sight of food without having a chance to try it. In that respect, Korea advertises and fails to deliver.

\section{Why Change?}

Addressing this issue can prove beneficial. Muslims make up one fifth of the world's population after all, and according to projections their numbers will continue to increase:

Nearly 1.6 billion Muslim people in 140 countries, including some 135,000 in Korea, consume halal-certified food products and the global market size was estimated to be worth $\$ 661.6$ billion as of 2010, according to the World Halal Forum. That swells to $\$ 2$ trillion when halal-certified beauty and other non-food products are added, the forum said. (Park, 2013, n.p.)

This sizable sector could become a lucrative consumer base for Korean cultural products. At the moment, due to the lack of halal food options, 
the number of foreign Muslim students has plateaued (Abdullah, 2014). An article in The Korea Times states, "If Korean universities ensured the availability of halal food for Muslim students, many more Muslim students would come to Korea to pursue higher education" (Abdullah, 2014, n.p.).

Korea set its eyes on other Asian countries with similar Confucian roots, and the USA, the benchmark against which it measures its progress. However, little to no attention is paid to the Middle East and Africa. There is a lot of unexplored potential there and it would be interesting to find out exactly what makes Korean dramas, for instance, resonate with Middle Eastern and African viewers - who are neither part of the West nor part of the Confucian tradition-and to develop products catering to their needs. Connecting different sides of Hallyu, such as education and cuisine, and branching out to new countries could very well help Hallyu become even more popular worldwide.

Hallyu maintains a strange duality: it tries to present itself as a global movement yet it is at the same time ethnically rooted. This is evident in my material and tangible bodily experience as a racialized Muslim. I was invited to Korea through Hallyu, yet I was also strangely barred and expelled through the lack of halal food. It is these "habits and gestures... [that] differentiat[e] 'others' into familiar (assimilable, touchable) and strange (unassimilable, untouchable)" (Ahmed, 2000, p. 44), thus positioning me as a strange body. My experience as an unassimilable cultural outsider complements the broader narrative positioning Hallyu as an easily received and consumable movement. Instead of depicting a straightforward consumption process which is unhindered by cultural and/or religious differences, my account reveals Hallyu as a phenomenon that needs to accommodate and embrace otherness on more than a superficial level. 


\section{References}

Abdullah, F. (2014, September 14). Halal food would attract more Muslim students. The Korea Times. Retrieved from: http://www.koreatimes.co.kr/www/news/opinon/2015/09/ 162_164524.html.

Adams, T. E., Jones, S. H., \& Ellis, C. (2015). Autoethnography. New York, NY: Oxford University Press.

Ahmed, S. (2000). Strange encounters: Embodied others in post-coloniality. New York, NY: Routledge.

Atkinson, P. (2006). Rescuing autoethnography. Journal of Contemporary Ethnography, 35(4), pp. 400-404. doi:10.1177/0891241606286980.

Bhabha, H. (Ed.). (1990). Nation and narration. NY, NY: Routledge.

Bhabha, H. (1994). The Location of culture. New York, NY: Routledge.

BON Factory (Production company). (2010). My girlfriend is a gumiho [Television series]. Seoul: Seoul Broadcasting System.

Boylorn, R. M., \& Orbe, M. P. (Eds.). (2014). Introduction: Critical autoethnography as method of choice. In Critical autoethnography: Intersecting cultural identities in everyday life (pp. 13-26). Walnut Creek, CA: Left Coast Press.

Butz, D., \& Besio, K. (2009). Autoethnography. Geography Compass, 3(5), pp. 1660-1674. doi:10.1111/j.17498198.2009.00279.x.

Chang, H., Ngunjiri, F.W., \& Hernandez, K. C. (2013). Collaborative autoethnography. Walnut Creek, CA: Left Coast Press.

Cho, H. (2005). Reading the 'Korean wave' as a sign of global shift. Korea Journal, 45 (4), pp.147-182.

Chua, B.H. (2010). Korean pop culture. Malaysian Journal of Media Studies, 12(1), pp. 15-24.

Chun, C. (Director). (2008). Lost baggage: Documentary on migrant workers in South Korea/ (잃어버린 가방) [Online video]. Retrieved from https://vimeo.com/47599510.

CJ E\&M (Production company). (2013). Let's eat [Television series]. Seoul:Total Variety Network.

Counihan, C. M., \& Kaplan, S. L. (Eds.). (1998). Food and gender: Identity and power (Vol. 1). Amsterdam, The Netherlands: Harwood Academic Publishers.

Dalessio, W. R. (2012). Are we what we eat? Food and identity in late twentieth-century American ethnic literature. New York, NY: Cambria Press.

Ellis, C., Adams, T., \& Bochner, A. (2011). Autoethnography:An overview. Forum Qualitative Sozialforschung/ Forum: Qualitative Social Research, 12(1). Retrieved from:http://www.qualitative-research.net/index. php/fqs/article/view/1589/3095.

Foreign residents make up 3\% of Korean population. (2011, December 16). The Korea Times. Retrieved from: http://www.koreatimes.co.kr/www/news/nation/2011/12/117_100923.html.

Group 8 (Production company). (2009). Boys before flowers [Television series]. Seoul: Korean Broadcasting System 2.

Hallyu now (KBSWorld $10^{\text {th }}$ anniversary special:The great transformation of the Korean wave (한류대전환)

Part 1). (2013, August 5). Retrieved from: https://www.youtube.com /watch?v=InmvHf9klv4.

Hamid, M. (2007). The reluctant fundamentalist. New York, NY: Harcourt, Inc.

Hoppes, S. (2014). Autoethnography: Inquiry into identity. New Directions for Higher Education, (166), pp. 63-71. doi:10.1002/he.20096.

Iglauer, P. (2012, April 1). Korea-Arab society actively builds up cultural bridges. The Korea Times. Retrieved from: http://www.koreatimes.co.kr/www/news/special/2012/04/139_108145.html. 
Jamal, A., \& Naber, N. (Eds.). (2008). Race and Arab American before and after 9/11: From invisible citizens to visible subjects. Syracuse, NY: Syracuse University Press.

Jang, H. J. (Producer). (2008). Family outing [Television variety show]. Seoul: Seoul Broadcasting Station. Jo, J. H. (Producer). (2003). Dae Jang Geum [Television series]. Seoul: Munhwa Broadcasting Corporation. Kapiszewski, A. (2006, May 22). Arab versus Asian migrant workers in the GCC countries. United Nations Expert Group Meeting on International Migration and Development in the Arab Region (15-7 May 2006), Beirut, Lebanon: n.p.

Khan, M., \& Ecklund, K. (2012). Attitudes toward Muslim Americans post-9/11. Journal of Muslim Mental Health, 7(1), 1-16. doi: http://dx.doi.org/10.3998/jmmh.10381607.0007.101

Kim, E.M., \& Ryoo, J. (2007). South Korean culture goes global: K-Pop and the Korean wave. Korean Social Science Journal, 34(1), pp. 117-152.

Kim, S. H. (Producer). (2005). My name is Kim Samsoon [Television series]. Seoul: Munhwa Broadcasting Corporation.

Korea Immigration Service, Ministry of Justice. (2015). KIS statistics 2014. Retrieved from: http://www. immigration.go.kr/HP/COM/bbs_01/Download.do? FileDir=/attach/imm/f2015/\&UserFileName=1. pdf\&SystemFileName=20150701229489_1_1.pdf.

Kuwait: Import requirements and documentation. (2005) In Office of the Bulgarian Economic and Commercial Counselor in Kuwait. Retrieved from: http://www.ecbg-kuwait.com/kuwait/import requirements.php.

Lee, H. M. (Producer). (2002). Winter sonata [Television series]. Seoul: Korean Broadcasting System 2.

Lee, U.J. (Producer). (2010). Pasta [Television series]. Seoul: Munhwa Broadcasting Corporation.

Nader, L. (2011).Ethnography as theory. HAU: Journal OfEthnographic Theory, 1(1), pp.211-219. doi :http:// dx.doi.org/10.14318/hau1.1.008.

Park, S. (2013, May 2). Food makers rush to secure 'halal' certification. The Korea Times. Retrieved from: http://www.koreatimes.co.kr/www/news/culture/2013/05/386_135000.html.

Pyo, M. S. (Producer). (2011). Flower boy ramyun shop [Television series]. Seoul:Total Variety Network.

Semaan, G. (2014). Arab Americans: Stereotypes, conflict, history, cultural identity and post 9/11. Intercultural Communication Studies, 23(2), 17-32. Retrieved from http://web.uri.edu/iaics/files/ Gaby-Semaan.pdf

Shim, D. (2006). Hybridity and the rise of Korean popular culture in Asia. Media, Culture \& Society, 28(1), pp. 25-44.

Shin, W.H. (Producer). (2012). Reply 1997 [Television series]. Seoul:Total Variety Network.

Shin, W. H. (Producer). (2013). Reply 1994 [Television series]. Seoul:Total Variety Network.

Shin, W.H. (Producer). (2016). Reply 1988 [Television series]. Seoul:Total Variety Network.

SSD/ Golden Thumb (Production company). (2012). King of dramas [Television series]. Seoul: Seoul Broadcasting Station.

Williams, L. A. (2010). Unsettling appetites: Asian American women writing food and subjectivity (Doctoral dissertation). Retrieved from ProQuest: http://search.proquest.com/docview/862357611. UMI 3449411.

Wong, S. C. (1993). Reading Asian American literature: From necessity to extravagance. Princeton, NJ: Princeton University Press. 
Xu, W. (2008). Eating identities: Reading food in Asian American literature. Honolulu, HI: University of Honolulu.

Yoon, H. S. (Producer). (2000). Autumn in my heart [Television series]. Seoul: Korean Broadcasting System.

DINA MAGDY ELDAKHAKHNY obtained her MA degree in English Literature from the University of Alexandria in 2014. Since 2011, she has been employed first as a demonstrator, and then as an assistant lecturer in the Department of English Language and Literature at Alexandria University. She is currently pursuing a doctoral degree at the Department of English Language and Literature, Yonsei University, Seoul, South Korea (corresponding author: dinamagdy88@gmail.com). 